\title{
Adult female harpacticoid copepods maintain their energy reserves by feeding while suspended during storms
}

\author{
Keith Suderman, David Thistle* \\ Department of Oceanography, Florida State University, Tallahassee, Florida 32306-4320, USA
}

\begin{abstract}
Adult females of some species of benthic harpacticoid copepods maintain their neutrallipid energy reserves while suspended by storms. To determine whether they do so by feeding in the water column or by reducing their metabolic rate, we subjected harpacticoids from a coastal site $\left(29^{\circ} 51^{\prime} \mathrm{N}, 84^{\circ} 31^{\prime} \mathrm{W}\right)$ to laboratory conditions that crossed factors of food and no food with suspension and no suspension. Adult females maintained their neutral-lipid levels when food was present and experienced a loss of neutral lipids when food was absent, whether suspended or not, demonstrating that adult female harpacticoid copepods maintain their neutral-lipid energy reserves when suspended by storms by feeding in the water column.
\end{abstract}

KEY WORDS: Meiofauna $\cdot$ Harpacticoida $\cdot$ Storms Disturbance

\section{INTRODUCTION}

Storms are a major feature of the shelf environment. They affect $100-\mathrm{km}$-scale areas, can occur several times per month (Cacchione et al. 1987), and can erode sediment at substantial water depths (Sherwood et al. 1994). Meiofauna living on the shelf are concentrated in the sediment layer put into motion by storms (Huys et al. 1986, Coull et al. 1989). Because these animals are small and have little mass, they will be suspended rather than move in bedload if the sediment around them erodes (Palmer \& Gust 1985). Thistle et al. (1995a) found that harpacticoids (the second most abundant meiofaunal taxon, Hicks \& Coull 1983) did not escape into the seabed when exposed to a simulated winter storm and inferred that harpacticoids will be suspended by natural storms. The presence of individuals of other meiofaunal taxa in the water column (Hagerman \& Rieger 1981, Shanks \& Edmondson 1990) may indicate that storms suspend near-surface-living meiofauna generally (but see Bell et al. 1988).

When a meiofaunal organism is suspended during a storm, it could benefit, for example, by being trans-

-Addressee for correspondence. E-mail: thistle@ocean.fsu edu ported to a more favorable location, by escaping temporarily from benthic predators or competitors (Service \& Bell 1987), or by gaining access to water-column food resources. However, a suspended individual could be transported to an unfavorable area (Palmer \& Gust 1985), be exposed to water-column predators (D'Amours 1988, Palmer 1988), or expend more energy than it can acquire.

The study of the consequences for meiofauna of suspension during storms has just begun. Thistle et al. (1995b) investigated the balance between energy intake and energy utilization during suspension by measuring the amount of stored energy (as neutral lipid, Carman et al. 1991) present in control and suspended individuals. They found that suspended adult male harpacticoids used significantly $(76 \%)$ more of their neutral-lipid reserves in just $2 \mathrm{~d}$ of suspension than did control adult males. In contrast, even $3 \mathrm{~d}$ of suspension had no detectable effect on the neutrallipid reserves of adult females.

Determining the mechanism that allows adult female harpacticoids to experience substantial periods of suspension without a net energetic cost is of considerable interest. Discovery that they do so by reducing their metabolic rate would reveal an unanticipated physio- 
logical capability of harpacticoids. Discovery that they do so by feeding in the water column would help determine whether water-column feeding is a relatively restricted adaptation among harpacticoids (Decho 1986, Pace \& Carman 1996) or whether it occurs more generally. Therefore, in this study, we sought to determine whether adult females maintained their stored energy reserves by feeding in the water column or by reducing their metabolic rate.

\section{MATERIALS AND METHODS}

Locality. The study site $\left(29^{\circ} 51^{\prime} \mathrm{N}, 84^{\circ} 31^{\prime} \mathrm{W}\right)$ was $6 \mathrm{~km}$ offshore of the Florida State University Marine Laboratory at $3 \mathrm{~m}$ depth (Fig. 1). The seabed was an unvegetated medium sand; the graphic median grain size (Folk 1968) was $271 \mu \mathrm{m}$. Divers observed sediment ripples of 10 to $20 \mathrm{~cm}$ wavelength and 1 to $3 \mathrm{~cm}$ helght on most visits, indicating reworking by waves.

To simulate suspension of harpacticoids by storms, we needed to know the duration of physical reworking of the sediment by storm-induced waves (hetediter 'reworking') at the site during the season of the experiment (September and October). We estimated reworking by measuring light intensity at hourly intervals for $34 \mathrm{~d}$ at $70 \mathrm{~cm}$ and $150 \mathrm{~cm}$ above bottom. Division of the difference between the 2 measurements by the value of the upper measurement yielded an index normalized to available light. This index is sensitive to local reworking but also to other processes that create a

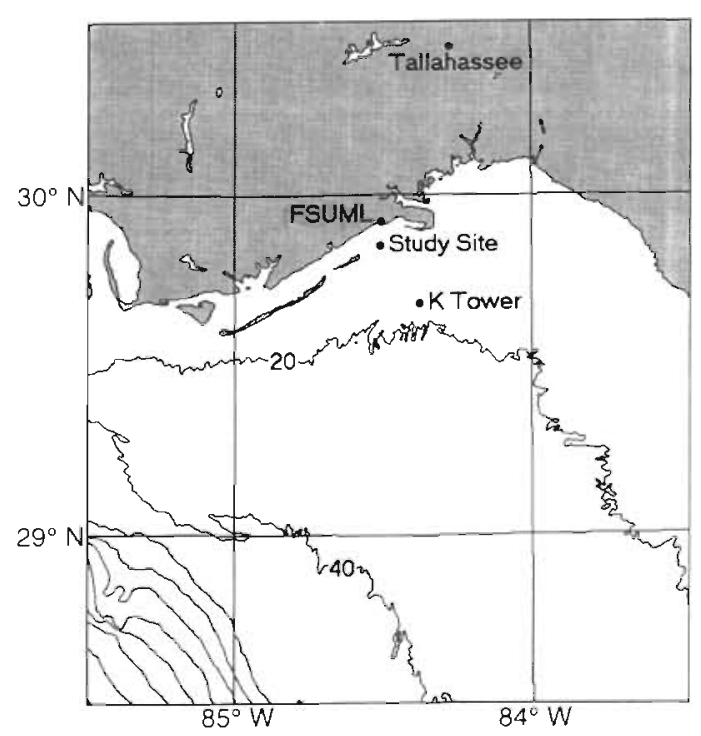

Fig. 1. Study site in the Gulf of Mexico off northern Florida USA, the location of the Florida State University Marine Laboratory (FSUML) where the experiment was done, and the comparison site ( $\mathrm{K}$ tower) studied by Thistle et al. $(1995 \mathrm{a}, \mathrm{b})$. Contours are in meters light gradient, e.g the advection of turbid water. To reduce the influence of such effects, we defined periods of local reworking as intervals when the index and the wind speed at the Florida State University Marine Laboratory (Fig. 1) increased abruptly from re]atively low background values (Fig. 2). This approach is limited because the index has no meaning at night and the winds were measured only once each day, but it was sufficient to detect periods of reworking of 28 , 52 , and $56 \mathrm{~h}$ between 14 September and 13 October 1996. G. Weatherly (pers. comm.) observed periods of reworking of similar duration during the same period in 1992 and 1993 at an $18 \mathrm{~m}$ site farther offshore (Ktower, Fig. 1). We therefore chose to mimic fall storms by suspending adult females for $2 \mathrm{~d}$.

To determine the depth to which storms reworked the seabed, we deployed 10 erosion posts (Thistle et al. 1995a) on 10 occasions. Estimates of reworking depth were averaged within each depioyment. The overail average of the 10 deployments was $1.67 \mathrm{~cm}$ (range 0.43 to $3.58 \mathrm{~cm}$ ). Accordingly, only harpacticoids found in the upper $2 \mathrm{~cm}$ of the seabed were considered in the siudy. This layer typically contains $90 \%$ of the harpacticoids at this site

Experimental treatments. Our experiment had 2 factors (suspension and food) with 2 levels each (with and without), resulting in these treatments: nonsuspension with food $(\mathrm{NS}+\mathrm{F})$, suspension with food $(\mathrm{S}+\mathrm{F})$, nonsuspension without food (NS-F), and suspension without food (S-F) (Table 1). If adult female harpacticoids feed while suspended, we would expect 'food' to be significant and the interaction term not to be significant. If adult female harpacticoids maintain their neutral-lipid levels while suspended by reducing their metabolic rate, we would expect 'suspension' and the interaction term to be significant.

For each replication of the experiment, ten $15.5 \mathrm{~cm}^{2}$ sediment samples were collected with a pole corer with remotely triggered end caps. Each core was assigned to a treatment at random. Two cores were immediately decanted (see below) onto a $63 \mu \mathrm{m}$ sieve. The sieve contents were frozen with liquid nitrogen. Analysis of adult female harpacticoids from these cores provided an estimate of ambient neutral-lipid levels (ASC, for the 'at-sea' control). The remaining 8 cores were placed in a covered water bath and brought to the laboratory.

We used decantation (Pfannkuche \& Thiel 1988) to extract the harpacticoids from the top $2 \mathrm{~cm}$ of each core. This layer was placed in a $1 \mathrm{I}$ graduated cylinder that was filled with $50-\mu \mathrm{m}$-filtered seawater and inverted 5 times. After $15 \mathrm{~s}$ in the upright position, the top $700 \mathrm{ml}$ were poured through a $63 \mu \mathrm{m}$ sieve. This procedure was repeated 5 times. Inspection of the unextracted fraction revealed that 90 to $95 \%$ of the harpacticoids were extracted $(n=3)$. 
Fig. 2. Wind speed (measured daily) at FSUML and turbidity index (measured hourly) at our site. The night-time index values have been omitted. We inferred that storms reworked the seabed on 16 September and 26 to 28 September

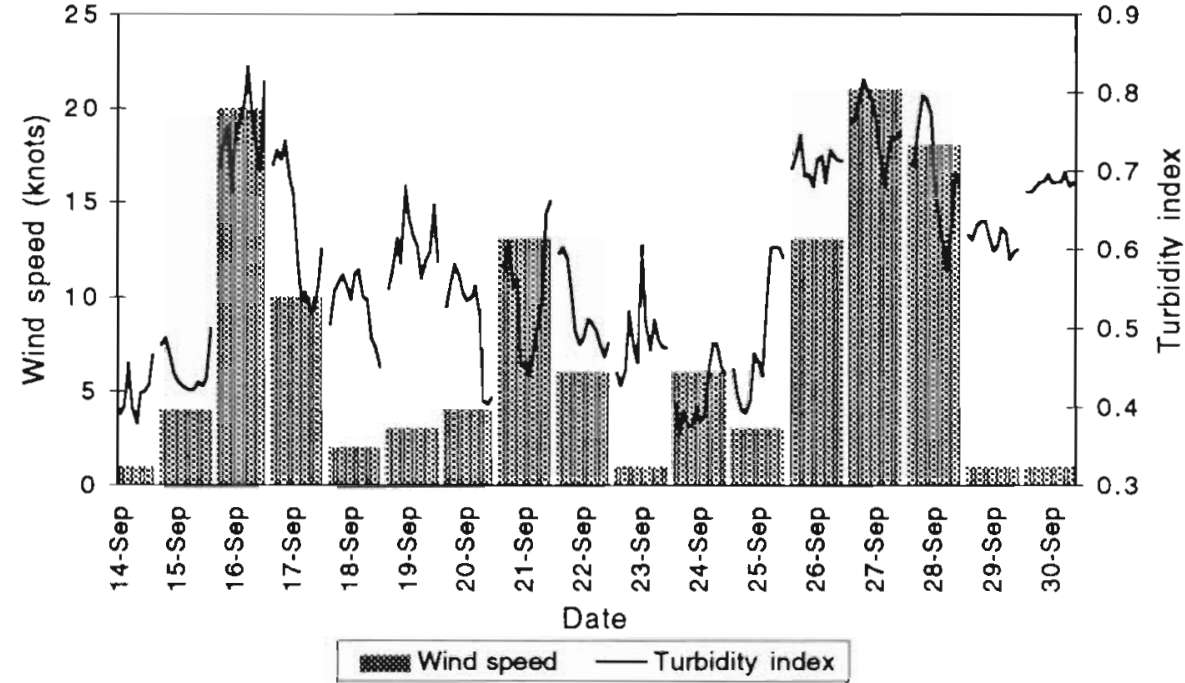

Table 1. Adult female harpacticoid copepods. Values are averages of square-root-transformed neutral-lipid scores. Number of individuals per average is shown in parentheses. ASC: at-sea control cores; NS+F: nonsuspension with food; $S+F$ : suspension with food; NS-F: nonsuspension without food; S-F: suspension without food

\begin{tabular}{|lccccc|}
\hline Replicate & ASC & NS $+F$ & S $+F$ & NS $-F$ & S-F \\
\hline 1 & $0.880(33)$ & $0.879(17)$ & $0.474(37)$ & Missing & $0.328(8)$ \\
2 & $0.621(15)$ & $0.689(6)$ & $0.601(20)$ & $0.065(2)$ & $0.000(1)$ \\
3 & $0.217(11)$ & $0.087(7)$ & $0.421(12)$ & $0.000(2)$ & $0.103(7)$ \\
4 & $0.306(35)$ & $0.288(14)$ & $0.323(20)$ & $0.367(5)$ & $0.495(3)$ \\
A.verage & 0.506 & 0.486 & 0.455 & 0.144 & 0.232 \\
\hline
\end{tabular}

The seawater used during the experiment lexcept for decantation) was collected with a 51 Niskin bottle (Teflon-covered spring, silicone o-rings) at the midpoint of the water column at the site and filtered through a $243 \mu \mathrm{m}$ sieve to remove large grazers. Once collected, its temperature was measured, and two $125 \mathrm{ml}$ aliquots were taken for measurement of the ambient ('at sea') chlorophyll a (chl a) content. The seawater used in S-F and NS-F was filter sterilized (0.2 $\mu \mathrm{m}$ filter).

Because bottom-associated harpacticoids that have been found to feed in the water column consume microalgae (Decho 1986), as do many shallow-water harpacticoids that feed in the benthos (Hicks \& Coull 1983, Carman \& Thistle 1985, Pace \& Carman 1996), the concentration of chl a was used as a measure of the amount of food available in the water column. To determine the effect of the experimental treatments on chl a concentrations, we collected water samples twice during each run, immediately after initiation of the treatments and 1 to $2 \mathrm{~min}$ before collection of the treated harpacticoids at the end of the experiment. See Thistle et al. (1995b) for the chl a procedure.
So that potential food organisms would not be introduced into the without-food treatments along with the harpacticoids, the harpacticoids had to be separated from the small amount of sediment remaining in the extracted fraction. The dishes containing the sieve contents were cooled $\left(\sim 1^{\circ} \mathrm{C}\right)$ until the harpacticoids were immobile, and the harpacticoids were then moved with pipettes to dishes of cold, filter-sterilized seawater. This procedure minimized sampling bias due to the movement characteristics of different species and slowed the harpacticoids' metabolism, which protected against a possible decline of neutral-lipid levels during processing When 50 adult harpacticoids (both males and females) had been collected for each without-food treatment, they were transferred through 2 baths of cold, filter-sterilized seawater and placed in the experimental vessels.

To suspend harpacticoids, we used a shear-driven annulus (Fukuda \& Lick 1980) (Fig. 3): a circular tank, $46 \mathrm{~cm}$ in diameter, with a $12 \mathrm{~cm}$ diameter center column. The seawater in the annulus was set in motion by rotation of a drive plate that rested on the surface of the water. Each annulus received 9.31 of seawater 


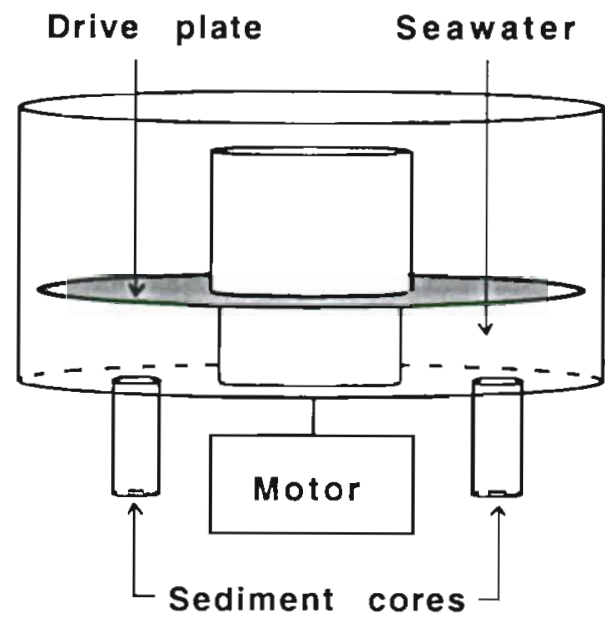

Fig. 3. Shear-driven annulus used in our experiments, showing cores mounted such that the surface of the sediment is coplanar with the bottom of the annulus as in NS+F. The other treatments lacked the cores

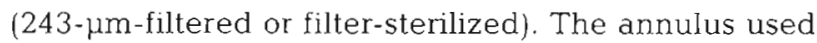
for a given treatment was selected at random.

The annuli were placed in an environmental chamber. Temperature was adjusted to keep the water in the annuli within $1^{\circ} \mathrm{C}$ of the temperature measured at the study site the day each replicate of the experiment was begun. Bright-white, fluorescent tubes were suspended over each annulus. Their height was adjusted. to provide light levels comparable to that at the midpoint of the water column as measured with a recording light meter (LiCor LI-1000). This level was chosen to provide the microalgae with a somewhat enhanced light level to help ensure their health during the experiment. The light:dark cycle was synchronized to sunrise and sunset.

The 4 treatments were established as follows. S+F was designed to approximate the concentration of harpacticoids and materials that the harpacticoids would experience when suspended during a storm. The decanted fluid from the top $2 \mathrm{~cm}$ of sediment from 2 cores was first refrigerated for a period equal to that necessary to live sort the harpacticoids for the withoutfood treatments (so the harpacticoids of both treatments would experience the chillingl and was then poured into the annulus. Decantation selected those materials (e.g. fine sediment) with settling velocities less than or comparable to those of harpacticoids, which are the materials that the harpacticoids would experience while suspended during a storm. We assumed that mixing of suspended material during a storm would involve the entire $3 \mathrm{~m}$ water column, so the harpacticoids and material extracted from the two $15.5 \mathrm{~cm}^{2}$ sediment cores would be suspended into a volume $2 \times 15.5 \mathrm{~cm}^{2} \times 3 \mathrm{~m}(=9.31)$ during a storm. By adding 243-4m-filtered seawater to the annulus to make the volume 9.31 , we approximated the appropriate concentration. The drive plate was rotated at $118 \mathrm{rpm}$, which was sufficient to suspend all but the heaviest particles (a few sand grains and shell fragments that were extracted with the harpacticoids during decantation, which moved as bedload). There were no areas of still sediment that might have allowed the harpacticoids to escape suspension. S-F was created in the same way, except that the seawater was filter sterilized and the harpacticoids were live sorted.

NS-F was also established in an annulus to provide uniformity between treatments. Live-sorted harpacticoids and filter-sterilized seawater were added, and the drive plate was installed but not rotated

$\mathrm{NS}+\mathrm{F}$ (intended to provide conditions as close to natural as possible) was established by insertion of two $10 \mathrm{~cm}$ deep, intact cores into the annulus, with the sediment surface flush with the floor of the annulus (Fig. 3). The annulus was filled with $243-\mu m$-filtered seawater. The drive plate was rotated slowly (12 rpm) to simulate non-storm levels of water motion. 'the sediment at the surface of the cores was still. To keep the oxygen levels in the sediment near ambient, we kept the color change marking the redox potential discontinuity (Rhoads 1974) at its initial depth by allowing seawater to percolate through the cores at 0.06 to $0.13 \mathrm{ml} \mathrm{min}{ }^{-1} \mathrm{~cm}^{-2}$ (McLachlan et al. 1981, Thistle et al. 1995b).

Establishing the without-food treatments required the additional manipulation of live sorting. To determine whether cooling and live sorting affected the neutral-lipid levels of adult females, we compared adult females that had been decanted, cooled to $\sim 1^{\circ} \mathrm{C}$, live sorted, rinsed through 2 changes of cold, filtersterilized seawater, and rewarmed to ambient temperature (i.e. live sorted) to adult females that had been decanted directly from ambient sediment (i.e. control). The average neutral-lipid score (transformed as in the main experiment, see below) of the live-sorted adult females (1.74) was nearly equal to that of the control adult females (1.97), and the $95 \%$ confidence intervals overlapped extensively $(1.08$ to 2.40 and 1.34 to 2.61 , respectively). Though these results suggested that live sorting did not alter neutral-lipid levels, in the main experiment, we cooled the S+F harpacticoids during the time the live-sorted harpacticoids were being processed to make the treatments as similar as possible.

We did not include sediment cores in the suspension treatments because cores would have provided the harpacticoids with potential refuges from suspension. To avoid an experimental design in which cores were present only in the nonsuspension treatments, we also omitted sediment cores from NS-F. Because the aver- 
age neutral-lipid scores and ranges of the 2 with-food treatments (one with cores and one without) are essentially the same (Table 1), the presence of the cores in $\mathrm{NS}+\mathrm{F}$ did not appear to cause the observed difference between the with- and without-food treatments (see below).

After the 2 d treatment period, we collected the harpacticoids from NS+F by decanting the top $2 \mathrm{~cm}$ of the intact cores and freezing the harpacticoid-containing fraction with liquid nitrogen. We collected the harpacticoids from the remaining 3 annuli by siphoning the water through a $63 \mu \mathrm{m}$ sieve and freezing the sieve contents with liquid nitrogen. The samples were stored at $-18^{\circ} \mathrm{C}$. The experiment was replicated 4 times between 11 September and 31 October of 1995. There was 1 annulus per treatment per run.

Neutral-lipid analysis. Following Thistle et al. (1995b), we estimated the energy reserves of adult females by measuring the amount of neutral lipid in each. The thawed harpacticoids were stained with Nile red (Kodak) (Carman et al. 1991). The stained harpacticoids were placed under an epifluorescent compound microscope equipped with filters optimized for Nile red (Thistle et al. 1995b). Images of adult females were captured and processed with the aid of an imageanalysis system (Coreco OC-300). First, a bright-field image of the urosome of each harpacticoid, excluding the prosome and the rami, was captured and its area was determined. An epifluorescent image of the urosome was then captured. This image was binarized (the threshold was adjusted for best match to the image as viewed through the microscope), and the area of the neutral-lipid deposits was measured. (The treatment source of the samples was unknown to the operator.) The harpacticoid was then repositioned, and bright-field and fluorescent images of the prosome, excluding the urosome, the legs, and the antennules, were captured as above. The total neutral-lipid area divided by the area (bright-field) of the urosome and prosome yielded a neutral-lipid score for each harpacticoid.

Although this method does not measure the mass of neutral lipid, it provides a relative measure of neutral- lipid content that is useful when the amount of neutral lipid is very small (Carman et al. 1991). The samples from each replicate experiment were analyzed as a group, with the order of the analysis within the group determined at random to avoid the possibility that changes during storage could affect the results.

Statistical analysis. The data from the main experiment (Table 1) were analyzed as a 3-way ANOVA with the experimental run as a blocking factor. The 2 fixed factors, suspension and food, had levels of suspension and nonsuspension and with food and without food, respectively. Because the individuals from an annulus were not independent experimental units, they were considered to be subsamples of a single treatment and averaged to yield 1 neutral-lipid score per annulus (Hurlbert 1984). The neutral-lipid scores were squareroot transformed (before averaging) to remove a right skew detected with residual analysis (Montgomery 1991). The transformed data met the assumptions of normality and equal variance.

\section{RESULTS}

The procedures used to establish the food levels in the 2 food treatments were successful. Inspection of Table 2 reveals that the chl a concentrations at the beginning and end of each run for the with-food treatments (columns $\mathrm{NS}+\mathrm{F}$ and $\mathrm{S}+\mathrm{F}$ ) were comparable to or larger than those for ASC. In contrast, the values for the without-food treatments (columns $\mathrm{NS}-\mathrm{F}$ and $\mathrm{S}-\mathrm{F}$ ) at the beginning and end of each run were much less than the values for ASC, and the differences were significant (1-tailed $t$-tests). In the without-food treatments, chl a levels were significantly less at the beginning and end of the experiment than those measured at sea (Table 2). The average of the without-food final chl a levels was $<2 \%$ of the average of the at-sea chl $a$ levels, so the amount of food available in the without-food treatment was much reduced

To determine whether experimental procedures other than the treatments (e.g transportation from the

Table 2. Chlorophyll a concentrations $\left(\mu \mathrm{g}^{-1}\right)$ for at-sea controls and treatment annuli at the beginning and end of each run. Data from 1 run were lost. Abbreviations as in Table 1

\begin{tabular}{|c|c|c|c|c|c|c|c|c|c|}
\hline & \multirow[t]{2}{*}{$\mathrm{ASC}$} & \multicolumn{2}{|c|}{$\mathrm{NS}+\mathrm{F}$} & \multicolumn{2}{|c|}{$S+F$} & \multicolumn{2}{|c|}{$\mathrm{NS}-\mathrm{F}$} & \multicolumn{2}{|c|}{$S-F$} \\
\hline & & Start & End & Start & End & Start & End. & Start & End \\
\hline & 2.57 & 4.74 & 2.40 & 4.95 & 4.19 & 0.07 & 0.01 & 0.03 & 0.01 \\
\hline & 2.51 & 6.42 & 3.73 & 2.86 & 3.37 & 0.07 & 0.01 & 0.10 & 0.01 \\
\hline & 2.76 & 2.42 & 3.38 & 4.68 & 2.60 & 0.06 & 0.09 & 0.07 & 0.10 \\
\hline Average & 2.61 & 4.53 & 3.17 & 4.16 & 3.39 & 0.07 & 0.04 & 0.07 & 0.04 \\
\hline
\end{tabular}


Table 3. Three-way ANOVA of transiormed neutral-lipid scores from adult females. Factors are food, suspension, and run (a blocking factor)

\begin{tabular}{|lccccc|} 
Source & SS & df & MS & $F$ & $p$ \\
\cline { 1 - 2 } Food & 0.318 & 1 & 0.318 & 5.43 & 0.048 \\
Suspension & 0.003 & 1 & 0.003 & 0.05 & 0.829 \\
Run & 0.197 & 3 & 0.066 & 1.46 & 0.297 \\
Food $\times$ Suspension & 0.012 & 1 & 0.012 & 0.21 & 0.659 \\
Error & 0.469 & 8 & 0.059 & & \\
Total & 0.999 & 14 & & & \\
\hline
\end{tabular}

field to the laboratory, handling during the establishment of the experiment, and the general conditions during the experiment) altered harpacticoid neutrallipid scores, we compared neutral-lipid scores from the ASC cores (the best estimate of conditions in the field) to neutral-lipid scores in NS+F (the closest experimental approximation of conditions in the field) (Table 1). The average neutral-lipid scores for ASC and NS+F (0.506 and 0.486 , respectively) were essentially the same, and the $95 \%$ confidence limits $(-0.461$ to 1.473 and -0.666 to 1.638 , respectively) overlapped exten-

Table 4. Harpacticoid fauna used in this study. Because the harpacticoid fauna of our site was largely undescribed, adult female harpacticoids were assigned to numbered working species. The taxonomic affinities of the working species were determined with the aid of Wells' (1977) key, Huys et al.'s (1996) key, and the primary literature and are given below. Ranks of the 10 most abundant species are shown

\begin{tabular}{|c|c|c|c|}
\hline $\begin{array}{l}\text { Species } \\
\text { no. }\end{array}$ & Family & Species name & $\begin{array}{c}\text { Abundance } \\
\text { rank }\end{array}$ \\
\hline 201 & Laophontidae & Paralaophonte brevirostris & \\
\hline 203 & Cletodidae & Enhydrosoma longifurcatum & \\
\hline 204 & Leptastacidae & Leptastacus cf coulli & 8 \\
\hline 205 & Thalestridae & Paradactylopodia sp. & 2 \\
\hline 208 & Ectinosomatidae & Halectinosoma sp. A & \\
\hline 209 & Ectinosomatidae & Halectinosoma sp. B & \\
\hline 21.0 & Parastenhelidae & Parastenhelia cf ornatissima & 1 \\
\hline 211 & Harpacticidae & Zausodes arenicolus & \\
\hline 212 & (anthocamptidae & Mesochra cf. pygmaed & \\
\hline 214 & Ectinosomatıdae & Hastigerella cf. leptoderma & 4 \\
\hline 216 & Cletotidae & Rhizolhrix sp. & \\
\hline 217 & Laophontidae & Laophontesp. & \\
\hline 219 & Ectinosomatidae & Ectinosoma sp. & 3 \\
\hline 220 & Diosaccidae & Robertgurneya sp. & \\
\hline 222 & Longipediidae & Longipedia sp. & 5 \\
\hline 236 & Canthocamptidae & cf. Mesochra & \\
\hline 240 & Diosaccidae & Pholenota cf. spatulifera & 10 \\
\hline 241 & Ameridae & Praeleptomesochra sp. & \\
\hline 24.2 & Paramesochridae & Kliopsyllus sp. & \\
\hline $242 a$ & Paramesochridae & Paramesochra sp. & 9 \\
\hline 243 & Diosaccidae & Haloschizopera sp. & 6 \\
\hline 244 & Diosaccidae & Amphiascoides sp. & \\
\hline 260 & Harpacticidae & Zausodes sp. & 7 \\
\hline 263 & Ameridae & Paraleptomesochra sp. & \\
\hline
\end{tabular}

sively. To this extent, the establishment and running of the experiment did not alter neutral-lipid scores artifactually.

The average neutral-lipid scores from the 4 treatments (Table 1) were compared ( 3 -way ANOVA). The average of the with-food treatment level observations was significantly greater than that of the without-food treatment level observations (Table 3 ). The 2 levels of the suspension. factor did not differ significantly, and the interaction term was not significant (Table 3). The missing value (Run 1, NS-F) was estimated as the average of the other NS-F values, and 1 degree of freedom was removed from the error term

\section{DISCUSSION}

Although Thistle et al. (1995b) found that adult female harpacticoids did not use a detectable amount of neutral lipid while suspended, they could not determine the mechanism involved. Our experiment was designed to determine whether adult females were teeding while suspended or reducing their meidbolic rate. Because the neutral-lipid scores were unaffected when food was present, but decreased when food was absent (Table 1), we infer that adult female harpacticoids can feed when food is available. Because the interaction between food and suspension is not significant, we infer that their ability to feed is not significantly affected by suspension. Therefore, we conclude that they are able to feed in the water column during a storm, and this feeding is sufficient to meet their metabolic needs during storm-induced suspension. If the adult female harpacticoids were reducing their metabolism while suspended, 'suspension' and the interaction term would have been significant.

The first hints that ordinarily benthic harpacticoids could feed in the water column came from Decho's (1986) work, in which he found in laboratory studies that Microarthriaion littorale (Poppe) swam into the water column to feed during simulated high water. This result was counterintuitive because the mouthparts of harpacticoids appeared to be adapted for scraping microbes from sediment particles. In particular, harpacticoids lack the long, plumose setae on the second maxillae characteristic of herbivorous pelagic copepods. Pace \& Carman (1996) examined this issue using feeding experiments 
that better approximated field conditions and concluded that benthic feeding was the dominant mode, although 3 of the 4 species they studied could ingest food from the water column. In our study and that of Thistle et al. (1995b), individuals of all species (Table 4) were pooled, so it is not clear whether all species or a subset respond to suspension in this way. However, the species at our site do not overlap with those studied by Decho (1986) or Pace \& Carman (1996), so water-column feeding is not restricted to the species that these authors studied. The mechanism, however, remains unknown.

Thistle et al. (1995b) found that adult male harpacticoids used much of their neutral lipids after $2 \mathrm{~d}$ of suspension in storm-like conditions and suggested that adult males either could not feed while suspended or were expending energy at a greater rate than they were acquiring it. Because the morphologies of the mouth parts of adult male and adult female harpacticoids are alike and adult females can feed while suspended under storm-like conditions, it is unlikely that adult males cannot. Future work on suspended adult males should focus on the possibility that they behave differently from adult females while suspended such that they use disproportionate amounts of energy or reduce their feeding.

As an aside, a 1-way ANOVA between S+F and NS $+F$ repeats Thistle et al. (1995b). They found that adult female harpacticoids did not differ from controls in their neutral-lipid levels after 2 or 3 d of suspension in conditions that simulated winter storms. The present study was conducted in shallower water ( 3 vs $18 \mathrm{~m}$ ) at a site $24.7 \mathrm{~km}$ from theirs (Fig. 1) during the fall. We found no difference between the neutral-lipid scores of adult females in $\mathrm{S}+\mathrm{F}$ and NS $+F$. This result is unlikely to arise from a lack of statistical power. The averages of $\mathrm{NS}+\mathrm{F}$ and $\mathrm{S}+\mathrm{F}$ are nearly equal, and comparison of the entries for each replicate in Table 1 shows that the larger value is equally likely to be in either of these 2 treatments. This result suggests that Thistle et al.'s (1995b) findings are not site-specific. It appears that this effect occurs in this region in both fall and winter. It would be of interest to know if it occurs on the shelf in other regions.

For some time, it has been known that sedimentdwelling meiofauna occur in the water column (Hagerman \& Rieger 1981, Palmer \& Brandt 1981), and there has been considerable interest in possible costs and benefits (Palmer 1988). Our results suggest that, for adult female harpacticoids, being in the water column (at least during a storm) is energetically benign. If there are risks and benefits, they will have to be sought among other consequences of suspension, such as water-column predation or dispersal.
Acknowledgements. D. Balkwill and R. Iverson loaned equipment. L. Porter helped in the laboratory and in the field Comments from these individuals improved the text: L. Bouck, K. Carman, J. Chanton, S. Ertman, N. Marcus, D. Meeter, M. Palmer, and A. Thistle. We are grateful for their kind help. The research was supported, in part, by NSF grant OCE8911181. Contribution no. 1093 of the FSU Marine Laboratory.

\section{LITERATURE CITED}

Bell SS, Hicks GRF, Walters K (1988) Active swimming in meiobenthic copepods of seagrass beds: geographic comparisons of abundances and reproductive characteristics. Mar Biol 98:351-358

Cacchione DA, Grant WD, Drake DE, Glenn SM (1987) Storm-dominated bottom boundary layer dynamics on the northern California continental shelf: measurements and predictions. J Geophys Res 92:1817-1827

Carman KR, Thistle D (1985) Microbial food partitioning by three species of benthic copepods. Mar Biol 88:143-148

Carman KR, Thistle D, Ertman SC, Foy M (1991) Nile red as a probe for lipid-storage products in benthic copepods. Mar Ecol Prog Ser 74:307-311

Coull BC, Palmer MA, Myers PE (1989) Controls on the vertical distribution of meiobenthos in mud: field and flume studies with juvenile fish. Mar Ecol Prog Ser 55:133-139

D'Amours D (1988) Vertical distribution and abundance of natant harpacticoid copepods on a vegetated tidal flat. Neth J Sea Res 22:161-170

Decho AW (1986) Water-cover influences on diatom ingestion rates by meiobenthic copepods. Mar Ecol Prog Ser 33: $139-146$

Folk RL (1968) Petrology of sedimentary rocks. Hemphills, Austin, TX

Fukuda MK, Lick W (1980) The entrainment of cohesive sediments in freshwater. J Geophys Res 85:2813-2824

Hagerman GH Jr, Rieger RM (1981) Dispersal of benthic meiofauna by wave and current action in Bogue Sound, North Carolina, USA. PSZN I: Mar Ecol 2:245-270

Hicks GRF. Coull BC (1983) The ecology of marine meiobenthic harpacticoid copepods. Oceanogr Mar Biol Annu Rev $21: 67-175$

Hurlbert SH (1984) Pseudoreplication and the design of ecological field experiments. Ecol Monogr 54:187-211

Huys R, Gee JM, Moore CG, Hamond R (1996) Marine and brackish water harpacticoid copepods. The Dorset Press, Dorchester

Huys R, Herman RL, Heip C (1986) Seasonal fluctuations in vertical distribution and breeding activity of a subtidal harpacticoid community in the Southern Bight, North Sea. Neth J Sea Res 20:375-383

McLachlan A, Dye A, Harty B (1981) Simulation of the interstitial system of exposed sandy beaches. Estuar coast Shelf Sci 12:267-278

Montgomery DC (1991) Design and analysis of experiments, 3rd edn. Wiley, New York

Pace MC, Carman KR (1996) Interspecific differences among meiobenthic copepods in the use of microalgal food resources. Mar Ecol Prog Ser 143:77-86

Palmer MA (1988) Dispersal of marine meiofauna: a review and conceptual model explaining passive transport and active emergence with implications for recruitment. Mar Ecol Prog Ser 48:81-91

Palmer MA, Brandt RR (1981) Tidal variation in sediment densities of marine benthic copepods. Mar Ecol Prog Ser 4: $207-212$ 
Palmer MA, Gust G (1985) Dispersal of meiofauna in a turbulent tidal creek. J Mar Res 43:179-210

Pfannkuche O. Thiel H (1988) Sample processing In: Higgins $\mathrm{RP}$, Thiel $\mathrm{H}$ (eds) Introduction to the study of meiofauna. Smithsonian Institution Press, Washington, DC, p 134-145

Rhoads D (1974) Organism-sediment relations on the muddy sea floor. Oceanogr Mar Biol Annu Rev 12:263-300

Service SK, Bell SS (1987) Density-influenced active dispersal of harpacticoid copepods. J Exp Mar Biol Ecol 114:49-62

Shanks AL, Edmondson EW (1990) The vertical flux of metazoans (holoplankton, meiofauna, and larval invertebrates) due to their association with marine snow. Limnol Oceanogr 35:455-463

Sherwood CR, Butman B, Cacchione DA, Drake DE, Gross

Editorial responsibility: Otto Kinne (Editor),

Oldendorf/Luhe, Germany
TE, Sternberg RW, Wiberg PL, Williams AJ III (1994) Sediment-transport events on the northern California continental shelt during the 1990-1991 STRESS experiment. Cont Shelf Res 14:1057-1062

Thistle D, Weatherly GL, Ertman SC (1995a) Shelf harpacticoid copepods do not escape into the seabed during winter storms. J Mar Res 53:847-863

Thistle D, Weatherly GL, Wonnacott A, Ertman SC (1995b) Suspension by winter storms has an energetic cost for adult male benthic harpacticoid copepods at a shelf site. Mar Ecol Prog Ser 125:77-86

Wells JBJ (1977) Keys to aid in the identification of marine harpacticoid copepods. Zoology Department, University of Aberdeen

Submitted: July 21, 1997; Accepted: January 19, 1998

Proofs received from author(s): March 9, 1998 